\title{
Penerapan Ornamen Motif Kaligrafi Khuffi Pada Masjid Jami Al-Irsyad
}

\author{
Ima Siti Latifah ${ }^{1}$, Cherry Darmawan ${ }^{2}$ \\ ${ }^{1,2}$ Desain Interior, Fakultas Desain, Universitas Komputer Indonesia, Bandung \\ Email: ${ }^{1}$ imasitilatifah.is@gmail.com, ${ }^{2}$ cherry.dharmawan@email.unikom.ac.id
}

\begin{abstract}
Abstrak: Tulisan mendeskripsikan tentang penerapan ornamen kaligrafi khuffi pada Masjid Jami Al-Irsyad. Masjid Jami Al- Irsyad merupakan masjid yang menerapkan penggayaan modern tanpa menghilangkan citra masjid sebagai tempat ibadah umat islam. Ornamen merupakan bentuk karya seni visual berupa simbol yang memiliki makna tersendiri dan dipergunakan sebagai peghias atau aksen dekorasi ruangan. Ornamen kaligrafi adalah bentuk serapan dari huruf arab yang disusun dengan proporsi sehinga membentuk karya seni yang dapat terlihat secara visual tanpa mengubah arti dari kalimat yang digunakan. Ornamen Kaligrafi khat khuffi merupakan jenis ornamen kaligrafi dengan bentukan huruf tegas yang bersudut. Khat ini biasa digunakan sebagai ornamen bagunan dengan konsep arsitektur islam modern, karena bentuk khat ini memiliki sifat kebaruan. Selain itu, Pembahasan lain yang dikemukakan yaitu mengenai ciri khas bentuk, fungsi dan makna pada setiap ornamen kaligrafi khuffi. Metode penelitian ini menggunakan metode kualitatif deskriptif dengan cara mengidentifikasi makna, fungsi dan kesinambungan penggunaan motif kaligrafi khuffi pada Masjid Jami Al-Irsyad. Hasil yang akan dicapai yaitu apa kesinambungan penerapan motif kaligrafi khuffi pada Masjid Jami Al-Irsyad yang memiliki penggayaan modern.
\end{abstract}

Kata kunci: Ornamen, Kaligrafi Khuffi, Masjid.

Abstract: This paper describes the application of khuffi calligraphy ornaments to the AlIrshad Mosque. Al-Irsyad Mosque is a mosque that implements modern style without removing the image of the mosque as a place of worship for Muslims. Ornament is a form of visual art in the form of a symbol that has its own meaning and is used as decoration or accent of room decoration. Calligraphy ornaments are a form of absorption of Arabic letters arranged in proportion so that they form a work of art that can be seen visually without changing the meaning of the sentence used. Calligraphy Ornaments khat khuffi is a type of calligraphy ornament with angular formations. This khat is commonly used as a ornament of bagunan with the concept of modern Islamic architecture. because this form of khat has a novelty nature. In addition, another discussion that was put forward was that of the characteristics of form, function and meaning in each ornament of calligraphy khuffi. This research method uses descriptive qualitative method by identifying the meaning, function and continuity of the use of khuffi calligraphy motifs at Al-Irsyad Mosque. The result that will be achieved is what is the continuity of the application of the khuffi calligraphy motif at the Al-Irshad Mosque which has a modern style.

Keywords: Ornaments, Khuffi Calligraphy, Mosque.

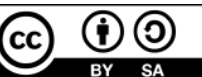




\section{PENDAHULUAN}

Ornamen merupakan bentuk karya seni visual berupa simbol yang memiliki makna tersendiri dan dipergunakan sebagai peghias atau aksen dekorasi ruangan. Ornamen biasanya dibuat menyerupai bentukan yang ada di alam atau berisi rangkaian tulisan yang tersusun dan memiliki suatu makna guna menjunjung nilai keserasian agar tercapai suatu tujuan nilai keindahan yang memiliki makna pada setiap bentuk yang diterapkan[1]. Ornamen kaligrafi adalah bentuk serapan dari huruf arab yang disusun dengan proporsi sehinga membentuk karya seni yang dapat terlihat secara visual tanpa mengubah arti dari kalimat yang digunakan. Ornamen Kaligrafi khat khuffi merupakan jenis ornamen kaligrafi dengan bentukan huruf tegas yang bersudut. Khat ini biasa digunakan sebagai ornamen bagunan dengan konsep arsitektur Islam modern, karena bentuk khat ini memiliki sifat kebaruan.

Masjid Jami Al-Irsyad digunakan sebagai objek penelitian karena memiliki konsep penggayaan yang tidak menampilkan citra arsitektur masjid pada biasanya, namun dengan menerapkan penggayaan modern tanpa menghilangkan citra arsitektur masjid dengan menerapkan ornamen kaligrafi khuffi yang memiliki bentuk tegas sehingga memiliki kesinambungan konsep bentuk antara bentuk kaligrafi khuffi dan bentuk arsitektur Masjid Jami Al-Irsyad.

\section{METODE}

Dalam penelitian ini, metode yang digunakan adalah metode deskriptif kualitatif dengan cara observasi untuk mengamati kesesuaian konsep dan fungsi motif kaligrafi khuffi yang diterapkan pada arrsitektur Masjid Al-Irsyad. Deskriptif dicapai dengan cara menjelaskan bentuk ornamen motif kaligrafi khuffi, keberadaan letak ornamen, serta mengetahui makna penerapan ornamen pada arsitektur masjid.

\section{HASIL DAN PEMBAHASAN}

\section{Ornamen Kaligrafi}

Ornament kaligrafi adalah seni rupa yang menggabungkan unsur garis dan keindahan Islami, yang bersumber dari ayat Al'Quran yang memiliki makna dan arti tertentu [2]. Ornamen dalam arsitektur masjid memiliki pola khas tersendiri sebagai hasil karya seni Islam. Pola ornamen terdiri dari motif tumbuh-tumbuhan, serta motif seni ukur dan bentuk-bentuk kaligrafi Arab (Situmorang, 1993: 6). Ornamen biasanya menjadi salah satu bentuk khas yang menjadi citra arsitektur islam, seperti masjid, sarana pendidikan islam, dan bangunan lain yang memiliki identitas bangunan islam. Ornamen pada masjid ditujukan sebagai hiasan yang dapat memperindah tampilan masjid. Biasanya ornamen Islam dapat ditemukan pada bagian, mihrab hingga hiasan pada bagian luar Masjid. 
Jenis-jenis kaligrafi diantaranya:

\section{Khattu Al-Naskhi}

Khat ini merupakan pokok dasar kaligrafi. Bentuk tulisan ini banyak digunakan dalam penulisan ayat-ayat Al-Quran, buku-buku ilmiah maupun tulisan sehari-hari.

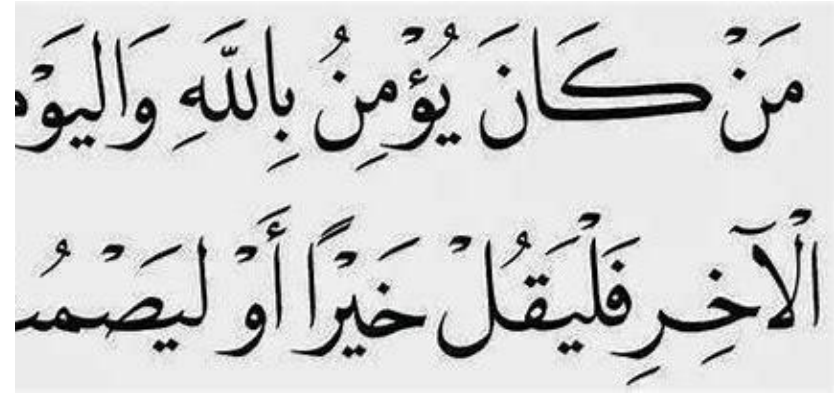

Gambar 1. Bentuk penulisan Khat Naskhi Sumber : www.arabicCalygrafy.com (2010)

\section{Khattu Al-Sulusi}

Khat ini merupakan jenis khat dengan teknik penulisan dengan bentuk lekukan huruf yang detail dan agak tebal, keindahan khat ini terletak pada penataan huruf yang serasi dan sejajar dan disertai harakat dan hiasan-hiasan huruf.

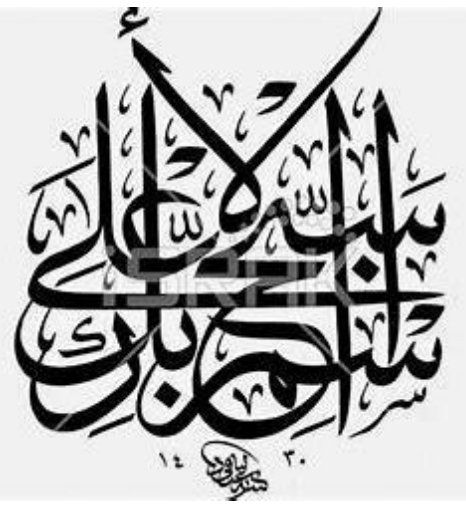

Gambar 2. Bentuk penulisan Khat Al-Sulusi

Sumber : www.arabicCalygrafy.com (2010)

\section{Khat Al-Kuffi}

Khat ini memiliki bentuk yang berbeda dari biasanya yaitu dengan mengubah bentuk lengkungan khas huruf arab menjadi bentukan tegas yang bersudut. Khat ini biasa digunakan sebagai ornamen bagunan dengan konsep arsitektur islam modern, karena bentuk khat ini memiliki sifat kebaruan. 


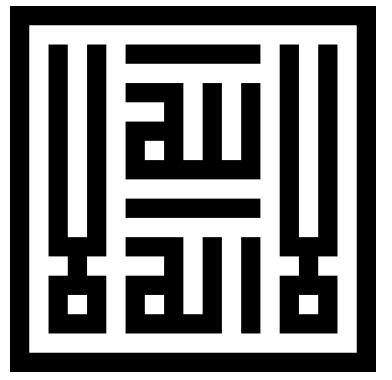

Gambar 3. Bentuk penulisan Khat Al-Kuffi

Sumber : www. arabicCalygrafy.com (2010)

\section{Masjid}

Masjid merupakan tempat ibadah umat Islam, yang dibangun agar umat mengingat, mensyukuri, dan ,menyembah Allah SWT Ibadah terpenting yang dilakukan di mesjid adalah shalat yang merupakan tiang-tiang agama Islam dan kewajiban ritual sehari-harinya, yang memungkinkan seorang Muslim berjumpa dengan Tuhannya lima kali sehari dalam semalam [3]. Salah satu fungsi dari Masjid yaitu sebagai tempat untuk memberikan wawasan umatNya dan memberikan orientasi untuk berdakwah. Selain itu, masjid memiliki fungsi sebagai lembaga pendidikan yang mana setiap umat dapat membaca dan belajar Al'Quran, Bejar mengenai akidah dan akhlak yang baik sebagai seorang Muslim [4].

Masjid memiliki elemen-elemen penting yaitu:

\section{Muqranas (kubah)}

Muqranas merupakan bentuk 3 dimensi berupa lekukan yang membentuk kubah, terletak dibagian atas bagunan yang membentuk ruang dengan lekuk 3 dimensi hal ini merupakan simbol dari makna keagungan Tuhan Yang Maha Esa.

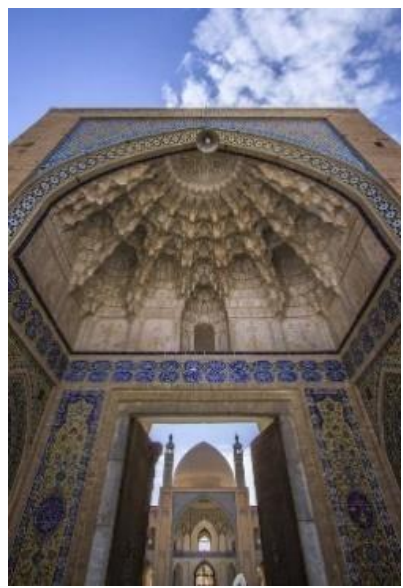

Gambar 4. Muqranas (kubah) Sumber : Art Of Islam (2012) 


\section{Mihrab (Kiblat)}

Mihrab merupakan area berbentuk ceruk atau lekukan tiga dimensi yang terletak di bagian depan masjid, Mihrab berfungsi sebagai arah kiblat.

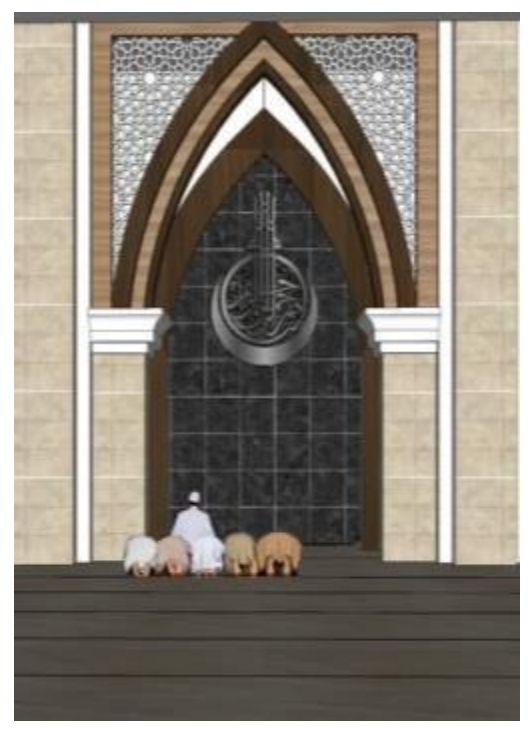

Gambar 5. Mihrab (kiblat)

Sumber : Art Of Islam (2012)

\section{Area Shalat}

Area shalat merupakan bagian paling luas yang berada di dalam masjid yang dipergunakan untuk melaksanakan shalat berjamaah, shalat sendiri, mengaji dan melaksanakan kajian atau yang biasa disebut ceramah.

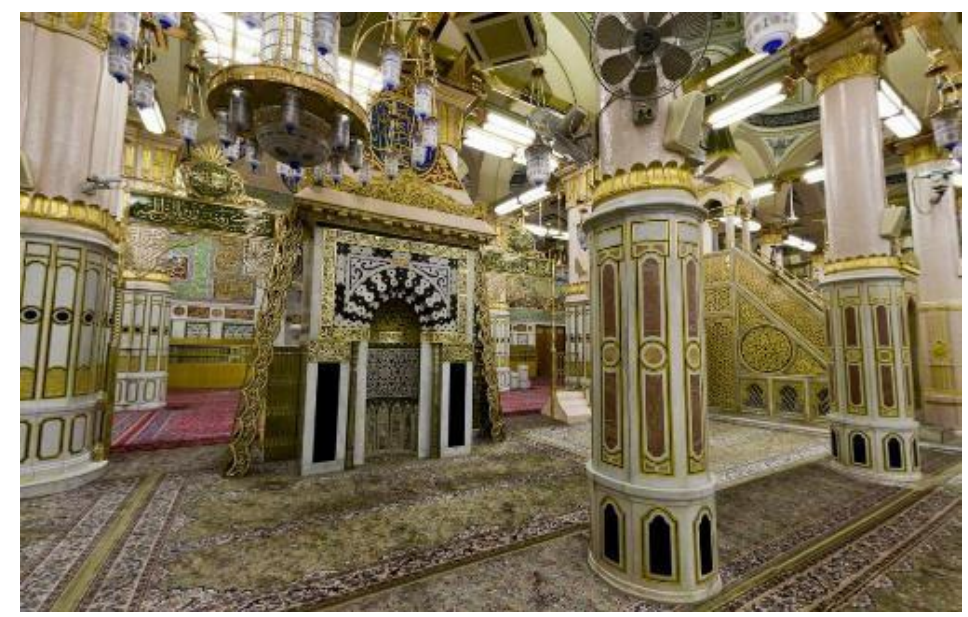

Gambar 6. Area Ahalat

Sumber : Art Of Islam (2012) 


\section{MESJID JAMI AL-IRSYAD}

Masjid Jami Al-Irsyad merupakan mesjid yang berdiri didalam golongan Nahdatul Ulama. Masjid ini terletak di Jl. Parahyangan KM. 2,7, Kota Baru Parahyangan, Cipeundeuy, Padalarang, Kabupaten Bandung Barat, Jawa Barat 40553 [5].

Masjid Jami Al-Irsyad memiliki arsitektur dengan penggayaan modern yang menimbulkan citra berbeda pada bangunan masjid. Hal ini terlihat dari bentuk arsitektur bangunan Masjid Jami Al-Irsyad yang menyerupai bentuk kubus tanpa adanya muqrannas (kubah) di bagian atas arsitektur bangunan tersebut.

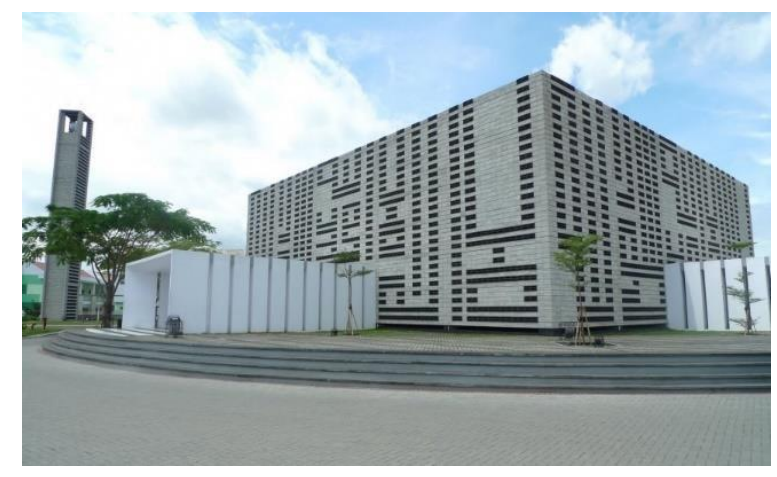

Gambar 7. Mesjid Jami Al-Irsyad

Sumber : www.alirsyad.or.id

\section{Ciri khas Arsitektur Bangunan Mesjid Al'Irsyad}

Bentuk ruang dalam yang dimiliki masjid ini pun terlihat sederhana tanpa penerangan yang berlebih, tanpa detail ornamen gaya klasik atau khas timur tengah. Konsep yang diadaptasi dari Ka'bah dan nilai-nilai Islam yang diterapkan pada Masjid Al- Irsyad menjadi pertanyaan akan makna dalam Ka'bah dan nilai-nilai Islam yang diterapkan pada bentuk Masjid Al-Irsyad sehingga menjadi pemilihan konsep dan menjadikannya memiliki bentuk yang berbeda dengan masjid lainnya.

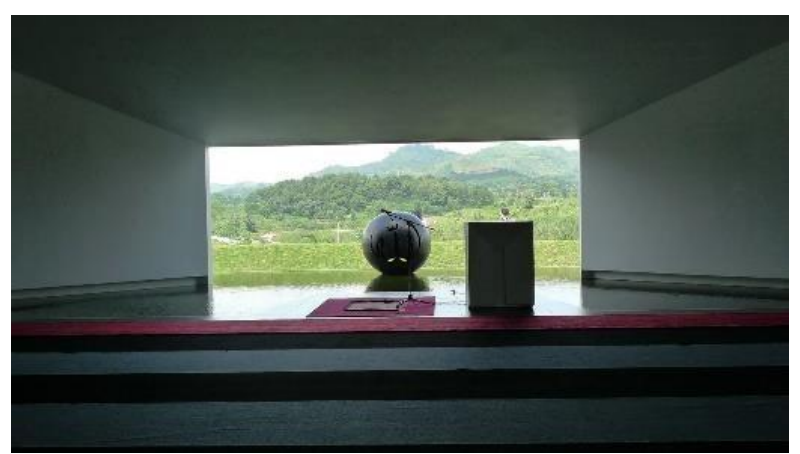

Gambar 8. Bentuk Mihrab Masjid Jami Al-Irsyad Sumber : www.alirsyad.or.id 
Bentuk mihrab Masjid Jami Al-Irsyad memiliki mihrab terbuka dengan aksen batu alam berbentuk lingkaran bola yang menjadi petunjuk arah titik kiblat. Konsep ini diadaptasi dari bentuk Ka'bah.

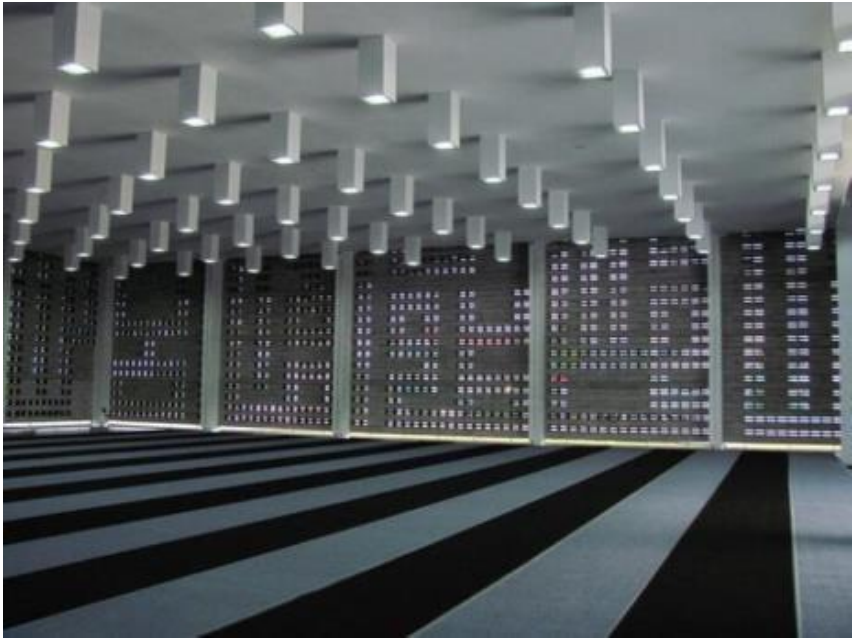

Gambar 9. Interior Masjid Jami Al-Irsyad

Sumber : www.alirsyad.or.id

\section{Penerapan Motif Kaligrafi Khuffi Pada Arsitektur Bangunan Masjid Jami' Al-Irsyad}

Penerapan ornamen motif kaligrafi khuffi pada arsitektur bangunan Masjid Jami Al-Irsyad yaitu terletak pada bagian fasad bangunan. motif kaligrafi khuffi tersebut tidak hanya berfungsi sebagai estetika fasad bangunan, namun berfungsi sebagai bukaan penghawaan yang di susun sehingga berbentuk Ornamen motif kaligrafi Khuffi.

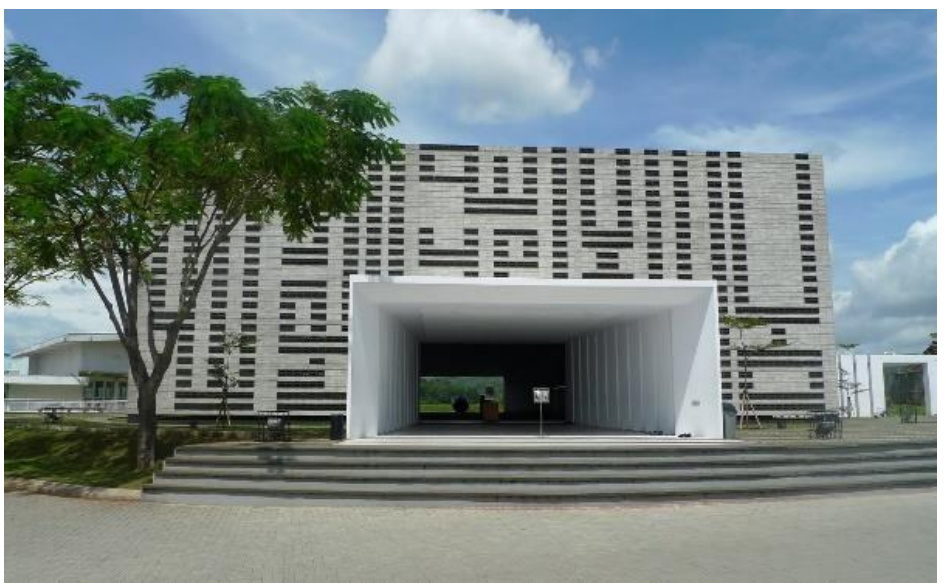

Gambar 9. Exterior Masjid Jami Al-Irsyad

Sumber : www.alirsyad.or.id 
Ornamen motif kaligrafi Khuffi yang diterapkan pada arsitektur bangunan Masjid Al-Irsyad merupakan rukun Islam yang pertama yaitu Syahadat yang berbunyi :

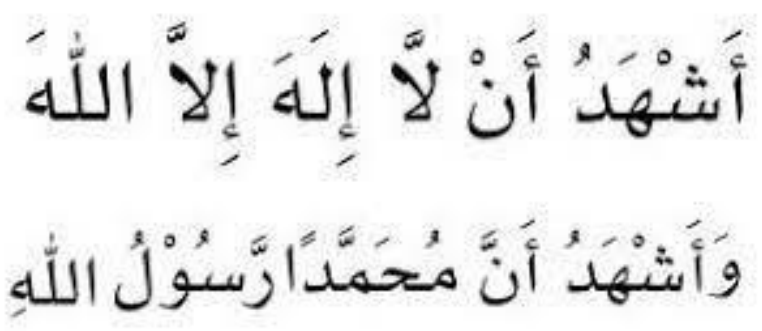

Artinya : Aku bersaksi bahwa tidak ada Tuhan melainkan Allah. Dan aku bersaksi bahwa Nabi Muhammad adalah utusan Allah.

\section{KESIMPULAN}

Masjid Jami Al-Irsyad memiliki arsitektur dengan penggayaan modern yang menimbulkan citra berbeda pada bangunan masjid. Hal ini terlihat dari bentuk arsitektur bangunan Masjid Jami Al-Irsyad yang menyerupai bentuk kubus tanpa adanya muqrannas (kubah) di bagian atas arsitektur bangunan tersebut. Bentuk ruang dalam yang dimiliki masjid ini pun terlihat sederhana tanpa penerangan yang berlebih, tanpa detail ornamen gaya klasik atau khas timur tengah. Konsep yang diadaptasi dari Ka'bah dan nilai-nilai Islam yang diterapkan pada Masjid Al-Irsyad menjadi pertanyaan akan makna dalam Ka'bah dan nilai-nilai Islam yang diterapkan pada bentuk Masjid Al-Irsyad sehingga menjadi pemilihan konsep dan menjadikannya memiliki bentuk yang berbeda dengan masjid lainnya. Penerapan ornamen motif kaligrafi khuffi pada arsitektur bangunan Masjid Jami Al-Irsyad yaitu terletak pada bagian fasad bangunan. Motif kaligrafi khuffi tersebut tidak hanya berfungsi sebagai estetika fasad bangunan, namun berfungsi sebagai bukaan penghawaan yang disusun sehingga berbentuk ornamen motif kaligrafi Khuffi.

\section{DAFTAR PUSTAKA}

-------. (n.d). Kamus Besar Bahasa Indonesia, (daring) Tersedia di: https://kbbi.web.id/estetika

Barliana. (2008). Perkembangan Arsitektur Masjid: Transformasi Bentuk dan Ruang. (daring). Tersedia di: https://ejournal.upi.edu

Dharmawan, C. (2015). Bentuk Masjid Berdasarkan Teknik, Material dan Motif (daring). Tersedia di: https://ojs.unikom.ac.id/index.php/wacaciptaruang/article/view/1382

Hidayat, A. (2014). Masjid Dalam Menyikapi Peradaban Baru. (daring). Tersedia di: https://ejournal.iain.purwokerto.ac.id 
Katarina, W. (2012). Studi Bentuk dan Elemen Arsitektur Masjid di Jakarta dari Abad 18 - Abad 20, (daring). Tersedia di: https://www.journal.binus.ac.id

Mochammad. (2017). Sejarah perkembangan Masjid Jami’ Al-Irsyad, (daring). Tersedia di: https://www.alirsyad.or.id

Sativa. (2011). Arsitektur Islam Berbasis Al'Quran dan Sunnah. Jakarta : NALARs Volume 10 nomor 1.

Supatmo. (2019). Nilai Multikultural Ornamen Pada Masjid. (daring). Tersedia di: https://journal.unnes.ac.id

Umar. (2014). Integrasi Konsep Islami dan Konsep Arsitektur Modern Pada Bangunan Masjid. (daring). Tersedia di: https://ejournal.stitek.binataruna.ac.id

Urtabeta, N. (2012). Deskripsi Tipologi dan Pendekatan Perancangan Masjid Modern. (daring). Tersedia di: https://ejournal.gunadarma.ac.id 